\title{
A Tecnologia do CD-Rom na Informação em Saúde
}

Jussara da Silva Long*

O CD - Rom (Compact Disc Read Only Memory), que pode ser traduzido por Disco Compacto-Memónia somente para leitura, é um disco de plástico que obedece a padrōes internacionais e é reproduzido da mesma forma que o disco compacto digital para áudio, amplamente conhecido. Sua única diferença está na maior exigência com relação à detecção e correção de erros de leitura, o que exige um controle de qualidade mais sofisticado.

Lançado no mercado em 1986, o CD - Rom caracteriza-se por sua alta capacidade de armazenamento que é de 550 megabytes, o que significa: mais de 550 milhões de letras, números ou símbolos especiais; mais de 200 mil páginas de textos datilografados, em papel A 4, em espaço simples; mais de 1500 disquetes de 360 by tes ou 300 mil fichas de catálogo de livros.

Toda esta capacidade pode ser acessada através de um microcomputador PC/XT ou PC/AT com sistema operacional DOS, capaz de manipular os dados lidos do novo periférico (normalmente obtido com o programa Microsoft Compact Disc Extension MSCDEX), e um leitor de $C D$ - Rom, que vem acompanhado de um cabo, uma placa e um disquete com o programa chamado Driver.

Utilizando esta tecnologia, o Centro Latino-americano e do Caribe de Informação em Ciências da Saúde - Bireme, lançou a mais completa e atualizada base de dados especializada na produção intelectual do profissional de saúde do Brasil, da América Latina e do Caribe, que por diversas razōes estava ausente dos serviços intemacionais de índices e resumos.

A partir de 1979 o Bireme iniciou a produção desta base de dados, hoje denominada LILACS, que tem como um de seus subprodutos o Index Medicus Latino-Americano (IMCA) que indexa artigos publicados em 450 periódicos biomédicos

$\mathrm{Na}$ sua 4: edição (set/89) em $\mathrm{CD}-\mathrm{Rom}$, a base de dados LILACS, além de 63 mil registros, contém 16 mil termos do vocabulário $\mathrm{D}$ e CS, um catálogo coletivo de mais de 15 mil títulos de periódicos da área de saúde que fazem parte dos acervos de mais de 40 bibliotecas. E mais a base de dados Repidisca, com documentos das ciências do ambiente e engenharia sanitária, coletados pelo Centro Pan-Americano de Engenharia Sanitária e Ciências do Ambiente, e o seu tesauros. 
Além destas bases, a 4: edição de LILACS traz a base de dados LEYS, que contém referências da legislação de saúde vigente nos países da América Latina e do Caribe, cobrindo n período de jan/78 a ago/89.

Segundo estudo divulgado pelo Infotech, estimou-se que, ao final de 1988, havia 78.750 leitores de CDRom instalados no mundo. As perspectivas de mercado são de que 284 mil leitores de CD-Rom estarāo instalados na Europa em 1992, e 30 milhões de computadores pessoais estarăo em uso.

No mercado americano, cerca de 1 milhão de leitoras deverão estar instaladas etn 1990. Na América Latina e no Caribe o número de leitores não chega a 250.

O Sistema de Biblioteca da Fiocruz possui este equipamento, cedido pelo Bireme, através de convênio, instalado na Biblioteca de Manguinhos, e à disposiçăo dos usuários do Sistema que inclui as bibliotecas da ENSP, do IFF, do CPqRR, do CPqGM e do CPqAM.

BIBLIOGRAFIA CONSULTADA:

BRITO, Căudio J. = Disseminaçăo de informaçăo e a tecnologia do CD-Rom. Ci. Inf., 17 (1): 3-13, 1988.

LILACS CD-Rom. 1 (1) 1989. 